\title{
DA INTERVISUALIDADE: PINTURA E TEATRO
}

\author{
Juan Villegas ${ }^{2}$
}

\section{Resumo}

O texto reflete sobre uma linha de pesquisa teatral que enfatiza a análise das imagens visuais nos discursos teatrais e sua intervisualidade com outras práticas culturais. $\mathrm{O}$ autor discute os fundamentos teóricos e a história da pintura como elementos chaves nas construções visuais da cena contemporânea. Ainda aborda a reutilização do "tenebrismo" e apresenta uma análise do espetáculo, Mira'm se dicen tantas cosas.

Palavras-chave: intervisualidade, teatro e artes visuais, tenebrismo.

\begin{abstract}
This text draws on a research that enhances the analysis of visual images within theatre discourse and their intervisuality within other cultural practices. The author discusses the theoretical bases and the paint history as key elements in the contemporary theatre's visual construction. It also looks at the "tenebrismo" and presents an analysis of the production Mira'm se dicen tantas cosas.
\end{abstract}

Keywords: intervisuality, theatre and visual arts, tenebrismo.

\section{Proposta geral e objetivos}

O objetivo deste texto é chamar a atenção para uma linha de pesquisa teatral. Seu ponto de partida é o pressuposto de que o teatro é uma prática cultural discursiva que utiliza uma pluralidade de signos para comunicar mensagens nas quais os signos visuais constituem um componente fundamental. A proposta sugere um campo de pesquisa que enfatiza a análise das imagens visuais nos discursos teatrais e sua intervisualidade com outras práticas culturais.

Ainda que o tema se refira a uma diversidade de campos, entre os quais se deve incluir a história da pintura, a estatuária, os desenhos de malas, o cinema, as gravuras, os baixorrelevos, os grafites, a fotografia, o marketing, etc. Nesta ocasião enfatizarei os fundamentos teóricos e a história da pintura como fatores nas construções visuais que constituem as portas da cena, a reutilização do "tenebrismo" no teatro atual, para terminar com uma breve análise de um espetáculo, Mira'm se dicen tantas cosas, produzido e dirigido por Marta Carrasco, coreógrafa, bailarina e diretora espanhola. ${ }^{4}$

Da intervisualidade: pintura e teatro. Juan Villegas.
${ }^{1}$ Tradução do original em espanhol por André Carreira.

${ }^{2}$ Professor da University of California, Irvine / Universidad de Chile.

${ }^{3} \mathrm{~A}$ expressão "tenebrismo" faz referência originalmente ao uso de fortes contrastes entre claros e escuros na obra do pintor italiano Caravaggio (15731610), posteriormente 0 termo foi aplicado a uma corrente do barroco espanhol. [NT] ${ }^{4}$ Disponível em < http://www.martacarrasco.com/> 
${ }^{5}$ Vários livros chaves apareceram no ano 2000 , ainda que antes existissem várias publicações que se centravam em aspectos vinculados com a cultura visual. Uma lista de revistas especializadas dos anos 80 e 90 pode ser vista em Elkins, pp. 14-16.

${ }^{6}$ Livros importantes no processo de delimitação e desenvolvimento da disciplina são os de Nicholas Mirzoeff, Ian Heywood e Barry Sandywell (editores), Marita Sturken e Lisa Cartwright.

Proponho considerar que no processo de criação da visualidade de um espetáculo teatral, atuam como fatores condicionantes as artes visuais de seu tempo e a tradição visual do sistema cultural. Seu entendimento, ao mesmo tempo, opera a competência cultural-visual dos espectadores. Afirmo que estes fatores estão determinados pelos sistemas de preferências e de teatralidades legitimadas dentro do sistema cultural dos emissores e destinatários do discurso.

A hipótese específica com respeito à pintura e o teatro é que o dramaturgo, cenógrafo, e a diretora recorrem à história da pintura como referente para suas construções visuais no palco que, em alguns casos, a história da pintura constitui o principal referente que faz evidente o sentido.

Apesar de que cada dia há maior interesse nas produções visuais, o tema praticamente não foi pesquisado de modo sistemático em todas suas possibilidades. Os deslocamentos das teorias sobre os objetos culturais e a intensificação da cultura visual no nosso tempo, no entanto, permitiram o desenvolvimento de tendências teóricas e estudos práticos que abriram o caminho e proporcionaram alguns instrumentos.

\section{A cultura visual e os estudos visuais}

Uma das teorias que foram adquirindo maior legitimação acadêmica nos últimos anos é a dos estudos visuais, que começaram a estabelecer-se ao final da década de noventa. ${ }^{5}$ James Elkins, em 2003, afirmava que os estudos visuais constituem uma disciplina na qual se integram outras como história, história da cultura, história da arte, crítica de arte, fotografia e história da fotografia, práticas artísticas, pedagogia da arte, economia política, estudos póscoloniais, psicanálise, estudos culturais, antropologia social, antropologia visual, feminismo e estudos de gênero, teorias queer e estudos gay, cinema, comunicações, arqueologia, arquitetura, urbanismo, sociologia da arte, artes performativas e marketing. Isto que dizer que uma prática totalmente interdisciplinar.

Geralmente os Estudos Visuais não são considerados dentro dos Departamentos de Estudos Literários. Não se encaixam nos departamentos de Humanidades onde se estuda literatura. Tão pouco nos departamentos de Teatro. Tendem a existir nos de Estudos do Cinema, Media Studies e Antropologia.

Em termos gerais, entendo os Estudos Visuais como o campo que busca estudar as práticas visuais. ${ }^{6}$ Seu objeto é a cultura visual. Ainda quando a cultura visual poderia ser entendida como os signos visuais utilizados pelas diversas culturas, há uma tendência nas pesquisas qualificadas como Estudos Visuais em limitar o campo ao contemporâneo e à cultura popular 


\section{Urdimento}

dos últimos cinquenta anos. Elkins, por exemplo, afirma: "estudos da cultura visual (é) o resumo das práticas visuais populares desde a metade do Século XX ...”(ELKINS, 1980, p.36).

Para meus objetivos, prefiro entender a disciplina como a análise e interpretação das práticas visuais de todos os tempos, enfatizando sua historicidade e a especificidade de sua utilização tanto em suas práticas específicas como em suas inter relações.

\section{Alguns estudos sobre pintura e teatro}

O interesse pelos elementos visuais na cultura contemporânea, por outro lado, tem levado ao aparecimento de vários ensaios e livros que se referem aos elementos iconográficos no teatro, um dos quais é a pintura.

Em um convite para uma série de conferências, os organizadores, José Antonio Sánchez y Sigfrido Marín Begué (2004), assinalavam:

A pintura, às vezes, tem servido como meio de conservação da imagem teatral, em outras ocasiões, o teatro serviu de estímulo e modo para pintura [....] A partir da segunda metade do Século XIX, numerosos pintores se aproximaram ao teatro como um lugar onde plasmar suas ideias plásticas em forma de cenários para balés, óperas ou teatros de arte. Alguns criaram também obras cênicas nas que substituíam os pigmentos pela luz e o movimento e outros antepuseram às imagens a exploração do espaço cênico. ${ }^{7}$

No caso do mundo hispânico, uma das exceções são os estudos sobre Buero Vallejo, vários dos quais se referem ao próprio Buero como pintor. Estes destacam como sua prática pictórica e sua teoria da pintura se manifesta nos seus textos dramáticos e na seleção de pintores como protagonistas de algumas das suas obras (Velázquez-Goya). Dentro dos ensaios que vão nesta direção sobressai o de César Oliva, quem afirma que a pintura é um referente de sua produção dramática, ainda que um referente carregado de significação, dada a dedicação que o autor teve a essa arte. ${ }^{8}$

Outros estudos sugestivos são os de María José Palla, quem em A palavra e a imagem estuda a relação entre os textos de Gil Vicente e a pintura do Século XV, e indiretamente em Traje e pintura, onde, ao examinar o traje e suas implicações ideológicas, se refere à pintura e ao teatro. Conclui, por exemplo, que o teatro medieval europeu teve inegável

${ }^{7}$ Reproduzido no jornal digital $L a$ Cerca, 19 de outubro (2002). As conferências apresentadas no ciclo ainda não foram publicadas e um dos organizadores, José Sánchez, afirmou em março de 2003, que pensava preparar outro ciclo sobre o tema e logo publicarão um volume monográfico.

8 ("La pintura en el teatro de Buero Vallejo". Versão circulando em Rede). influência na pintura. As observações deste livro a respeito das descrições e reproduções dos trajes podem ser aplicadas às descrições dos mesmos nas peças de teatro do período. 


\section{Urdimento}

Um ensaio que propõe vários caminhos de pesquisa é $A$ análise do teatro através da iconografia. Uma metodologia interdisciplinar, de Francesc Massip, que propõe cinco modalidades de utilização da pintura no teatro. Uma delas é que denomina "documento direto", no qual o teatro se constitui no "sujeito iconográfico". Nos outros casos é um "documento indireto", no qual "podem ser considerados aqueles monumentos figurativos nos que se pode reconhecer, por via indutiva, o reflexo da linguagem cênica em um momento dado de sua história". O terceiro tipo se refere a "aquelas figurações com uma relação direta e orgânica com o espetáculo, e com um espetáculo determinado, que não foram produzidas como testemunho, mas sim como projetos". O quarto corresponderia "aos desenhos, plantas ou miniaturas que são memória do espetáculo e de sua encenação". Finalmente o quinto incluiria aqueles materiais "que documenta(m) a concepção de um teatro possível".

Ainda que o tema central não seja o do teatro e pintura, um longo ensaio de José Luis Plaza y Chillón inclui temas vinculados à inter relação entre ambas práticas. Junto a uma excelente bibliografia, o texto se centra na pintura das cenografias, comenta vários pintores e sua contribuição para a criação cenográfica, entre os quais destaca a Dalí e Picasso.

No campo da língua inglesa, é preciso recordar o número da revista 1Theatre Research International 22, 3 (1997) dedicado à iconografia e o teatro.

\section{As possíveis áreas de pesquisa da relação pintura-teatro}

${ }^{9}$ Nota do tradutor. A expressão "teatros nacionais" faz referências a salas de propriedade governamental tradicionalmente reconhecidos nos países da América Latina com essa denominação.
O campo de investigação teatro-pintura é bastante amplo. Em um ensaio publicado na revista Teatrae, sugiro, pelo menos, as seguintes áreas:

\section{1 - A decoração dos edifícios teatrais}

A consideração da relação pintura-teatro aparentemente mais externa ao teatro como produção cênica, é a da pintura e o edifício teatral. Aspecto que é de grande importância para a história das culturas na América Latina, especialmente quando se trata de "teatros nacionais" e salas vinculadas a instituições associadas com governos ou instituições locai ou nacionais. Desta maneira, os tetos pintados, por exemplo, constituem indícios dos sistemas de preferências dos setores culturais no poder e, com frequência, representam os ícones ou figuras simbólicas reverenciadas por estes setores.

Com relação a este aspecto, há outras pesquisas pouco trabalhadas, como é o caso, por exemplo, da vida e formação dos pintores/as participantes na "decoração" do teatro, a tecnologia, as escolas de pintura predominantes, o significado específico no contex to individualizado no momento de sua produção, a inter relação entre as pinturas e os espaços do edifício: o exterior, a sala de 


\section{Urdimento}

espera, as colunas, as abóbodas e, especialmente, a abóboda central. Cada espaço tem uma significação diferente e, consequentemente é necessário se perguntar pela seleção do tema, as personagens dos quadros, as técnicas empregadas e sua funcionalidade. Geralmente, nas salas à italiana dos grandes teatros oficiais, o espaço de maior importância é a abóboda central. Portanto, é ali, onde se encontra a pintura de maior significado e a mensagem pode ser mais evidente.

\section{2- Presença do teatro em pinturas}

Um dos aspectos que tem preocupado os historiadores do teatro é o da reconstrução de encenações do passado. Enquanto alguns sustentam sua impossibilidade, outros afirmam que é factível fazê-lo utilizando os documentos adequados. ${ }^{10}$ Dentro destes, são de grande valor as pinturas ou as gravuras que reproduzem cenas teatrais. ${ }^{11}$

Aqui a pesquisa envolve tanto a seleção de pinturas como a consideração das causas da seleção das cenas reproduzidas, sua significação social, ideológica e estética em seu tempo. ${ }^{12}$

a)Pinturas nas quais, sem ser reprodução ou representação de uma cena específica, se utilizam elementos teatrais cuja inspiração é uma cena teatral específica.

b)Pinturas que utilizam elementos cenográficos e teatrais, ainda que não se associem com encenações específicas ou encenações de momentos históricos determinados, como se acostuma mencionar ao comentar o quadro e afirmar que são "muito teatrais".

\section{3 - Reutilização de pinturas no teatro}

Por outro lado, existe um amplo campo de pesquisa na direção das tendências pictóricas, sua influência e presença no teatro. Este aspecto parece ser o mais sugestivo para a história do teatro, a análise do processo da construção visual de uma encenação e a interpretação de encenações específicas.

Sem analisar em profundidade, algumas das opções são as seguintes:

a)A utilização de pinturas no palco pode incluir desde ser um simples adorno -sempre significativo- até a inclusão de quadros como parte da cena. Às vezes é um retrato ou um quadro facilmente reconhecido pelos espectadores, ainda que ocupe um espaço pequeno ou a totalidade ou quase totalidade do fundo do palco.

b)A cenografia ou a descrição do cenário, no caso dos textos dramáticos, cria o ambiente e serve de fundo espacial das ações representadas. ${ }^{13}$

\footnotetext{
${ }^{10}$ Desenvolvi este aspecto em Para la interpretación do teatro como construção visual.

${ }^{11}$ No livro História do teatro argentino, editado por Osvaldo Pellettieri, há uma tentativa de incorporar materiais visuais como documentação, ainda que não haja uma análise dos documentos gráficos e sua relação com a encenação e a história do teatro.

${ }^{12}$ No Museo Antropológico de la Ciudad de México há figuras em greda associáveis ou definidas como cenografias teatrais.
}

${ }^{13}$ Há histórias do teatro que incluem reproduções de desenhos de cenários de espetáculos. Ver,por exemplo, Phyllis Hartnold. The Theatre. A Concise History. 
${ }^{14}$ Nesta perspectiva pode-se incluir a fotografia. Sobre fotografia e teatro ver a tese de doutorado de Polly Hodge.
A hipótese de trabalho neste caso seria que a pintura do cenário corresponderia temática e graficamente à sua funcionalidade para a ação, mas que a análise dos códigos pictóricos utilizados revela sua inserção dentro das tendências pictóricas de seu tempo.

c)A utilização de pintura na construção visual das personagens, o que pode incluir uma ampla gama de situações, desde a maquiagem e pintura dos rostos, incluindo a utilização de máscaras, até pinturas ou quadros identificáveis como material de referência.

d)A construção das cenografias e a descrição das mesmas cujo referente direto é uma pintura específica. Um exemplo desta última modalidade é o de Cristina Escofet, quando indica no texto dramático de Señoritas en concierto: Elas entram. Parecem mulheres de um quadro de Renoir. Ingênuas e românticas. Passeiam. Aceitam refrescos (241).

e)A construção de cenas que evocam imagens pictóricas ou pintores especificamente. Neste caso, um dos aspectos sugestivos é considerar as tendências pictóricas utilizadas, sua historicidade, sua funcionalidade e o significado possível da seleção. É o caso, por exemplo, de La verdad sospechosa, na versão de Héctor Mendoza, na qual as personagens se associam de imediato com pinturas de Zurbarán ao estarem todos vestidos como monges mercedários, inclusive as mulheres do grupo.

f)A construção visual de personagens em relação com quadros e retratos das personagens de seu tempo, já seja na aparência física, o modo de se vestir ou os objetos que se mostra no quadro ou retrato original. ${ }^{14}$ Com frequência, personagens teatrais aparecem identificados como de alguma época passada. A maior parte das vezes estas caracterizações provém de retratos de época, o que é especialmente evidente quando se trata de personagens históricos, ainda que a proposta não se limita a estes.

Qualquer destas linhas de pesquisa necessita de numerosos trabalhos e re-coleção de materiais que, do meu ponto de vista, os estudiosos do teatro descuidaram. Tal é o caso, por exemplo, da ausência de entrevistas com diretores e cenógrafos, pelo menos, nas quais se pergunte sobre sua consciência sobre o uso de imagens da história da pintura, quadro ou pintores/as específicos ou imagens das culturas populares ou canonizadas.

Frente a esta série de possibilidades e ampla gama de campos, se faz necessário propor uma teoria de investigação coerente. 


\title{
Os fundamentos teóricos: do teatro como construção visual
}

\author{
a)Do teatro e o imaginário visual
}

Desde a perspectiva proposta, o ponto de partida é que o teatro é um discurso que utiliza uma pluralidade de linguagens e signos para comunicar uma mensagem determinada. Dentro desta pluralidade de signos, os visuais constituem um elemento fundamental e, em algumas práticas teatrais, são os dominantes. Isso implica entender as imagens visuais como signos de um discurso, o qual por sua vez é um discurso integrado a outro discurso. Implica, além disso, entender as referências visuais implícitas, as que, com frequência, coincidem com as de outras representações visuais contemporâneas ao texto dramático ou teatral (baixorrelevos, pintura, murais, fotografia, cinema, por exemplo). Esta perspectiva supõe que todo sistema cultural envolve uma série de imagens e sistemas de percepção visual do mundo, que conformam um imaginário visual.

Proponho que, em um determinado momento histórico, coexiste na sociedade uma pluralidade de sistemas culturais com seus correspondentes imaginários visuais (sistema de signos visuais), alguns dos quais são legitimados social e esteticamente pelos poderes culturais. Deste modo, proponho que tanto os textos escritos como os visuais de um momento histórico correspondem a formulações e utilizações de um imaginário visual legitimado. Consequentemente, se coloca a possibilidade de configurar o modo visual definidor legitimado dessa cultura. A estratégia, então, exige considerar o discurso visual da cultura legitimada, a competência visual de produtores e espectadores, e os agentes formadores dessa competência.

Esta proposta envolve a re-semantização de vários conceitos:

\section{a)Do conceito de teatralidade e teatralidades}

Um conceito chave na proposta é o de teatralidade. Proponho entender teatralidade como um sistema de códigos no qual se privilegia a construção e percepção visual do mundo e no que os signos enfatizam a comunicação por meio de imagens. O mundo é percebido como palco no qual se atua e os emissores de signos emitem tanto signos gestuais como visuais e linguísticos. A teatralidade ou as teatralidades são construções que funcionam de acordo com os códigos culturais do produtor, e que requerem ser decifradas pelo receptor. Constitui uma construção cultural de setores sociais que codificam sua percepção do mundo e sua auto representação no palco social. Desde um ponto de vista semiótico, as teatralidades são portadoras de mensagens de acordo com os sistemas culturais dos quais são produtos ou dos quais se utilizam. 
Diferencio “teatralidade social” e "teatralidade estética”. A primeira é o conjunto de teatralidades que caracterizam uma determinada sociedade. Portanto, é uma construção que inclui numerosas categorias. Do mesmo modo que Barthes aponta que, na realidade, todos os códigos são culturais, acreditamos que é possível afirmar que todas as teatralidades são sociais.

Proponho que em um sistema ou subsistema cultural existe uma pluralidade de sistemas ou subsistemas de teatralidade, tais como a "teatralidade política”, "teatralidade pedagógica”, "teatralidade desportiva”, “teatralidade religiosa”, etc. Cada uma corresponde a sistemas de signos empregados nestas atividades pelos praticantes do sistema cultural". (Para la interpretación do teatro como construção visual).

A hipótese com que trabalho é que em cada momento histórico existe uma teatralidade legitimada que constitui o imaginário visual legitimado do sistema cultural. Esta teatralidade, sugiro, está vinculada aos setores produtores de objetos culturais, neste caso, os discursos teatrais, e tanto a seleção do objeto como seu modo de representação são funcionais em um processo de legitimação social, cultural ou estética dentro do circuito de comunicação de produtores e destinatários. Para isto se utilizam os códigos visuais correspondentes à cultura legitimada no sistema cultural.

\section{b)A competência cultural e visual}

A interpretação requer um destinatário com a competência cultural e visual que lhe permita decodificá-los. 1Entendo esta competência cultural como a capacidade do indivíduo e o grupo social para decifrar signos de um sistema cultural. A competência teatral implica na familiarização com os códigos teatrais e estéticos dentro do sistema cultural e teatral.

A competência cultural está determinada muitas vezes pela construção visual do passado levada a cabo pelas instituições (histórias ilustradas, a escola, livros escolares, revistas, o sistema educacional em geral) e outras artes visuais (escultura, pintura, arquitetura) dentro do sistema cultural ou outros sistemas culturais que constituem parte do imaginário social de produtores e espectadores.

Em nosso tempo, além dos meios tradicionais, há de se conceder considerável importância ao cinema e à televisão como agentes chaves na configuração visual do passado e na formação da competência visual dos espectadores.

Dentro desta proposição, é importante considerar que em cada momento histórico, os grupos sociais - já seja no poder ou com pretensões de alcançá-lo - buscam justificar sua permanência nele ou buscam substituir 
os grupos que o ostentam, utilizando e fundando seu imaginário no de uma instância do passado ou de outra cultura que pode contribuir para sua legitimação. Neste processo de legitimação se apropria das teatralidades - os signos, imagens e ícones visuais de uma cultura com potencialidade legitimadora - resignificando-as funcionalmente segundo seus próprios interesses e seus projetos políticos.

\section{Das intervisualidades}

Assim como em um momento se falou de "intertextualidades" a propósito dos textos literários, nas práticas visuais deveríamos falar de intervisualidades, mas não no sentido de "influência" de uma arte em outra, nem da presença de uma imagem de um texto visual em outro, senão no que refere ao uso de uma fonte comum de imagens constitutivas do sistema de visualidade de um sistema cultural. A este conjunto ou sistema de imagens usadas em objetos visuais considerados estéticos, denomino a teatralidade esteticamente legitimada. Esta teatralidade legitimada se constitui por preferência de imagens, referentes preferidos - reais ou artísticos-, a utilização de tecnologias preferidas e uma ideologia e imaginário social que dão sentido à seleção de imagens de acordo com seus destinatários específicos. A teatralidade legitimada implica, com frequência, uma competência cultural específica do destinatário ou espectador.

O caráter de construção cultural da teatralidade legitimada exige considerar a inter relação entre teatralidades artisticamente legitimadas, as ideologias dos setores produtores, a competência visual necessária dos potenciais receptores e os contextos histórico-sociais.

Dentro da ampla gama que implica a proposta, nesta ocasião quero limitar-me a examinar um aspecto da utilização da pintura como fator mediatizador na dimensão visual da encenação: a utilização de códigos visuais associáveis com as tendências pictóricas ou "escolas" de pintura.

\section{A pintura como fator mediatizador da construção visual no teatro}

As inter relações entre as práticas teatrais e as pictóricas, no entanto, são variadas e complexas, segundo sugeri anteriormente.

Quero limitar-me agora à utilização de códigos visuais associáveis com tendências pictóricas como referente da encenação. Ainda mais, dentro deste tema, focalizarei a uma tendência, o tenebrismo, utilizando como texto base o espetáculo de Marta Carrasco, Mira'm se dicen tantas cosas. A hipótese central é que uma tendência pictórica é um discurso funcional ao seu contexto histórico e que ao ser apropriado 
pelos produtores culturais de outro período e al utilizar alguns dos códigos da mesma, estes são re-funcionalizados para o novo contexto, portanto se preenchem com a ideologia e a problemática do grupo cultural no qual, são re-funcionalizados.

\section{Códigos de tendências pictóricas}

A história da pintura estabeleceu tendências dominantes vinculadas a momentos históricos. Seus códigos definidores e sua utilização prática variaram em distintos espaços, ainda que em termos gerais lhes são atribuídas certas características comuns. Tal é o caso de tendências como o românico, o renascimento, o barroco, o impressionismo, o cubismo ou o surrealismo, cada uma das quais se praticou de modo diferente na Alemanha, Espanha, França ou nos países da América Latina. Creio, no entanto, que cada "escola" de pintura se constitui por códigos e modos de representação que constroem imaginários sociais fundados nas ideologias das hegemonias políticas, econômicas ou culturais.

Considero, também, que os códigos definidores de cada tendência podem adquirir independência e ser apropriados por outras ideologias para comunicar os imaginários que as legitimam. Por isto, não é de se surpreender que, com frequência, o espetáculo teatral moderno contemporâneo evidencie características que se associam a “escolas” pictóricas de outras épocas e outras condições históricas. Deste modo, se fala de encenações realistas, tenebristas, surrealistas, picassianas, barrocas, primitivistas, etc. Como cada modalidade pictórica constitui um discurso visual surgido de condições históricas, culturais e tecnológicas específicas, são várias as perguntas que podem surgir quando são reutilizadas por práticas visuais em outro momento histórico. Por isso, não é de se surpreender que em um período no qual o discurso visual dos setores culturais produtores de discursos teatrais é definível, por exemplo, como "realista”, as cenografias ou as encenações correspondam ao mesmo sistema de imagens, já que a imagem do mundo do discurso teatral, as teatralidades legitimadas e o discurso visual podem ser semelhantes.

Em um período em que predomina a teatralidade "realista" bem podem se dar formas pictóricas "realistas" no teatro, já seja na cenografia ou na construção de imagens identificáveis por meio da gestualidade, o figurino, a coreografia, a iluminação. Neste caso, pode interessar especialmente a configuração de imagens teatrais que se distanciem dos modos dominantes. Este seria o caso, por exemplo, a colaboração entre Federico García Lorca e Salvador Dalí, quando ambos aspiravam a "renovar" o teatro espanhol do momento. Esta renovação não se limitava aos textos senão que, unido a isto, estava o da representação do palco. Lorca sugeriu, por exemplo, que na encenação de Mariana Pineda (1927), “a cena estará enquadrada em uma margem amarelada como uma velha estampa, iluminada em azul, verde, 


\section{Urdimento}

amarelo, rosa e azul claro" (VILCHES-DOUGHERTY, 1990, p.37). Salvador Dalí, ainda que parecia coincidir com Lorca em uma declaração, na prática não seguiu fielmente seus desejos e instruções. Segundo um comentário da época: “a apresentação cênica de Dalí acaba de dar caráter à obra, e aumenta a sugestão de um ambiente, estilizando seus elementos líricos e dramáticos. O último cenário, sobre tudo, é admirável” (42). Em um e outro caso, no entanto, se tratava de se distancias da convenção das construções visuais do palco associável ao discurso dominante do momento.

A pesquisa deste aspecto implica se perguntar pelos códigos originais, sua função em seu tempo, mudanças experimentadas em sua re-utilização no espetáculo teatral, e sua significação estética e ideológica no novo contexto.

\section{Pintura tenebrista ${ }^{15}$ e o teatro espanhol atual}

Dentro dos espetáculos espanhóis contemporâneos pode-se observar a recorrência de procedimentos visuais associáveis aos pintores tenebristas dos séculos XVI e XVII. Em alguns casos, constitui o código chave da encenação; em outros, sua utilização é parcial e fragmentada, como é o caso das produções do grupo andaluz La Zaranda. ${ }^{16}$

O código pictórico definidor da pintura tenebrista se funda na forte antítese de luzes e sombras, com frequência de fundos escuros dos quais parecem emergir objetos ou partes dos corpos fortemente iluminados. No caso da pintura se costuma indicar como exemplos característicos alguns quadros de Rembrandt nos Países Baixos, Tintoretto, Caravaggio e Ticiano na Italia, Joseph de la Tour na Francia, e Zurbarán na Espanha, ainda que são numerosos os pintores em todos os espaços europeus em cujas pinturas há características tenebristas. Há quem destacou traços tenebristas no El Greco, no período anterior à sua chegada à Espanha como se vê em El niño de la candoa (também conhecido como El soplón), por exemplo, o em alguns quadros de Velázquez.

O tenebrismo dos séculos XVI e XVII, também chamado "naturalismo” por alguns historiadores da pintura, corresponde predominantemente a uma pintura religiosa que, como todo discurso, buscava comunicar uma "mensagem" aos fiéis da época. Deste modo, segundo Bozal, estas pinturas revelam uma preocupação por detalhes naturalistas, por uma reconstrução acessível para o espectador, para os fiéis, que assim podiam reconhecer seu mundo cotidiano nos quadros. É esta preocupação pela fidelidade natural o que produz o tenebrismo... (1972, p.179). O mesmo Bozal, no entanto, faz notar as diversas funções da iluminação. Em alguns casos, enfatizava a temporalidade, manifestada no efeito do tempo no corpo dos indivíduos, por tanto o perecível e a corruptibilidade do corpo humano.

${ }^{15}$ Efeitos de iluminação que reforça o claro e escuro na pintura.

\footnotetext{
${ }^{16}$ Neste ensaio, não projetarei as propostas de procedimentos tenebristas no teatro latino americano, que coloca outros problemas que não discuto aqui. Há numerosos exemplos especialmente dentro do teatro cubano que enfatiza a imagem do mundo e ritos afrocubanos. Um dos espetáculos cubanos que não toca o tema da afrocubanidade diretamente, mas usa os procedimentos tenebristas, é 0 unipessoal de Vivian Acosta La virgen triste, do grupo Galiano 108. Neste espetáculo, as luzes, com palco escuro, se funda quase exclusivamente nas velas e o candelabro com que se desloca a protagonista no palco.
} 
${ }^{17} J$ osé de Ribera é considerado 0 máximo exponente da escola tenebrista dentro do Barroco espanhol. Nascem em Xátiva (Valência) em 1591.
Um exemplo fascinante que prova este ponto, e que confirma a interpretação de Ortega y Gasset da utilização dos mitos gregos no Barroco, é o do Cupido dormido de Caravaggio, já que os pesquisadores demonstraram que o menino pintado é, na realidade, um cadáver e a pintura enfatiza os detalhes dos começos da decomposição da carne. Nas pinturas de Francisco Ribalta e, especialmente, nas pinturas de santos e ermitãos ${ }^{17}$ de José de Ribera se privilegia os efeitos do tempo. Enquanto parte do corpo fica nas sombras, a luz ilumina setores do mesmo no que se adverte arrugas, flacidez da pele.

Em outras pinturas tenebristas se acentua a atemporalidade dentro da temporalidade, o que se põe de manifesto no uso da luz, na composição do quadro, a seleção dos objetos, a localização dos mesmos cenários do quadro. À vezes se enfatiza o primeiro plano (Caravaggio), ou se concentra em partes do corpo (as mãos, o rosto) fazendo desaparecer o resto: As figuras, desse modo, aparecem incompletas; se cortam horizontal e verticalmente não importa por onde (BOZAL, 1972, p. 187). O mesmo historiador aponta, a propósito das pinturas de freis de Francisco de Zurbarán (1598-1664?): "expressa melhor que nenhum outro a religiosidade monástica com tendências místicas que é modo das ordens religiosas da época..” (1972, p.184) e agrega a propósito do uso da luz em Zurbarán:

\section{A chave deste estilo radica fundamentalmente na luz.} Enquanto que os pintores anteriores utilizavam uma luz que servia - na maioria dos casos - para iluminar penosamente uma cena, uma luz que, por tanto, procedia de um foco explícito o implícito na tela de Zurbarán não ilumina, transfigura, e não procede de nenhum foco mais ou menos natural, mais ou menos real, senão das figuras mesmas, dos corpos mesmos de santos e monges (1972, p.184).

David Giralt, ao falar do barroco na França, aponta que uma das tendências é o "tenebrismo" e que Georges de la Tour é “criador de efeitos de luz procedentes de uma tocha ou vela que mistificam, interiorizam e endurecem as composições...” (1990, p. 84) no que é semelhante a El Greco de El niño de la candoa, antes mencionado, e que parece quase a inspiração de algumas das imagens do espetáculo que comentarei com maior detenção nas páginas seguintes.

A análise do espetáculo teatral, desde a perspectiva que emerge das colocações anteriores, cria vários problemas, que não vou enfrentar nesta ocasião: a diferença de meios, a diferença entre um texto visual estático e um texto visual em transformação constante, que, desde o ponto de vista sugerido, pode se considerar como uma sucessão continua de cenas pictóricas, ainda que o olhar tende a se deter em algumas com maior capacidade de atração. Estas se destacam por seu vínculo com imagens que formam parte da competência cultural e visual dos espectadores. 
A análise dos espetáculos teatrais desde esta perspectiva obriga a voltar às propostas de Adolphe Appia a princípios de século. ${ }^{18} \mathrm{~A}$ crítica teatral há destacado diversas funções da iluminação no espetáculo teatral. Com respeito ao teatro contemporâneo, a iluminação se converteu em um instrumento chave na produção de sentido do espetáculo. Pavis assinala que "hoje o iluminador - dono absoluto da luz - aparece comumente como o personagem chave da representação" (1998, p. 242) $)^{19}$

Helga Finter observa que, no que denomina o teatro pós- moderno, se dá uma tendência aos contrastes e observa: "também a cor e a iluminação são empregadas em contraste" (1994. p.38). E agrega: "também a iluminação trabalha com encenações em contraste: estas mudam a forma, a cor e a linha em seu predomínio e fazem saltar à vista as qualidades ocultas. Assim, a luz se faz o significante do olhar desejante, que se faz experimentável como condição da percepção que primeiro possibilita a compreensão" (1994, p.38). E ao comentar espetáculos de Wilson, destaca: "a luz alterna entre essa iluminação de claros e escuros que faz que os detalhes apareçam como um punctum, e a iluminação difusa de Hollywood, que faz o olhar se fundir na imagem total" (1994, p.39).

Dentro do teatro espanhol dos últimos anos, se destacou a existência de una tendência denominada "ritual", na que aparece, entre outras características de sua linguagem teatral, os contrastes de luz. Óscar Cornago, por exemplo, ao analisar vários espetáculos dentro desta tendência, especialmente com exemplos entre 1965 e 1975, se centra em Nacimiento, pasión y muerte de, por exemplo, ...tú, dirigida por Jesús Campos, do Grupo Taller de Teatro. Cornago aponta que: "fortes contrastes de luzes, ênfase das imagens, cheiros, cores e sons foram elementos básicos de uma linguagem que buscava uma comunicação sensorial com o público familiarizado, quase inconscientemente, com a iconografia apresentada" (1999, p. 73).

\section{O caso de Mira'm se dicen tantas cosas, da Companhia de Marta Carrasco}

Para finalizar a relação pintura-teatro quero destacar, em breve análise, o espetáculo Mira'm se dicen tantas cosas, da Companhia de Marta Carrasco. Em um ensaio anterior, propus três possíveis leituras, ainda que me inclinei por una leitura feminista, no sentido de que as teorias feministas tem impulsionado a desconstruir certos imaginários como fundados em padrões e cânones do patriarcado no qual a mulher é a vítima do sistema. Nesta dimensão, por exemplo, se destacaram vários traços recorrentes no discurso teatral feminista: a denúncia da violência contra o corpo da mulher, o uso paródico ou satírico de imagens construídas pelo patriarcado

${ }^{18}$ Ver Keir Elam, The Semiotics of Theatre and Drama, p. 84.

${ }^{19} \mathrm{O}$ mesmo Pavis, s.v A iluminação, faz uma lista de funções da luz no espetáculo teatral. Ver Diccionario do teatro, p. 242-243. 


${ }^{20}$ Propus várias
possibilidades de
interpretação deste
espetáculo em Do
grotesco desgarrado
en el teatro español
contemporáneo: El
caso de Mira'm se
dicen tantas cosas de
Marta Carrasco.

${ }^{20}$ Propus várias possibilidades de interpretação deste espetáculo em Do grotesco desgarrado en el teatro español contemporáneo: $E$ I Marta Carrasco. como definidoras da mulher, e o logocentrismo como instrumento de poder. Nesta construção patriarcal da mulher, a pintura canonizada do Ocidente cumpriu uma importante função ao legitimar e naturalizar seus modos de representação, os que, ao mesmo tempo, servem como sistema de referências na construção da mulher em espetáculos teatrais e outras práticas visuais. Por isto, a desconstrução das imagens utilizadas no palco são reveladoras do sentido. Ainda que em Mira'm se dicen tantas cosas aparece uma intervisualidade com uma pluralidade de tendências pictóricas e de pinturas específicas, quero enfatizar em primeiro lugar a evidente utilização de códigos do tenebrismo. ${ }^{20}$

O imaginário social fundador do mundo em Mira'm... pode ser pensado em duas dimensões: como um mergulho ou entrada no mundo do inconsciente ou como uma representação do mundo do patriarcado na qual se evidenciam a violência e exploração da mulher. $O$ dominante da construção do espaço cênico é fundo quase sempre nas sombras ou totalmente escuro, no qual se vislumbram objetos manchados. O primeiro plano é predominantemente o das ações físicas, com espaços abertos, onde se deslocam as personagens e os objetos se substituem. O espaço cênico se concebe como um constante contraste de luzes e sombras.

$\mathrm{Na}$ cena inicial, o espetáculo utiliza intensamente o contraste entre luz e sombras e instrumentaliza a iluminação, com o sistema de strobe-lights ou efeitos estroboscópicos, que permitem vislumbrar uma realidade escondida nas penumbras. Em outras instâncias a luz funciona como guia do olhar do espectador, fazendo desaparecer partes do cenário, enfatizando detalhes, privilegiando fragmentos dos corpos. Deste modo, o cenário se dilata ou se contrai, em um constante ritmo de transformações. A iluminação funciona como travelling cinematográfico, guia do olhar do espectador, silencia espaços, ou faz explodir espaços luminosos. Enquanto o tenebrismo dos Séculos XVI e XVII acentuava a corruptibilidade do corpo e do humano como processo que levava o ser humano a pensar no transitório da vida terrena e a eternidade da vida da alma, o tenebrismo em Mira'm... configura a realidade do mundo concebido patriarcalmente como espaço de sombras, do qual a diretora faz emergir episódios iluminados que evidenciam a violência contra o corpo da mulher. Se destacam imagens que ao ser iluminadas contra o fundo escuro revelam a falsidade da construção das imagens do patriarcado. Estas parecem reverenciar e respeitar a mulher, mas, na prática, reforçaram a posição da mulher dentro do mundo do patriarcado. A ironia está em que as próprias mulheres contribuíram para sua canonização ou legitimação. Dentro do espetáculo, a fonte da desconstrução é a paródia das imagens da mulher legitimadas na sociedade cristã do Ocidente. 
Urdimento


Cenas de Mira’m. Fotos Manuel Fernández. Festival Iberoamericano de Teatro, Cadiz, 2001. À esquerda, exemplo de contrastes de luz e sombra. À direita, exemplo de contrastes de luz e sombra.



Cena de Mira’m. Foto de Manuel Fernández. Exemplo de contrastes de luz e sombra.

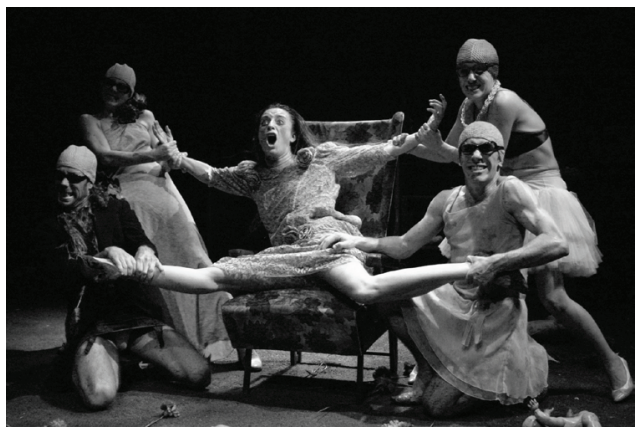

Cena de Mira’m. Foto de Manuel Fernández. Exemplo de representação da violência contra o corpo da mulher. 


\section{Urdimento}

Em uma das cenas, ao fundo, sobre caixas, aparece uma mulher sentada, cuja cabeça é substituída ou coberta por um quadro da Virgem. Em outra instância, uma mulher, com o rosto pintado que mostra sofrimento e uma jaula que cobre-lhe a cabeça, sai das sombras, enquanto se escuta uma canção de grande lirismo. Imagem que parece querer dizer que a mulher é como um pássaro enjaulado, enquanto que o discurso masculino lhe dedica canções de amor. Semelhante é a paródia da canção cantada por Edith Piaf, enquanto homens e mulheres atormentam a uma das mulheres.

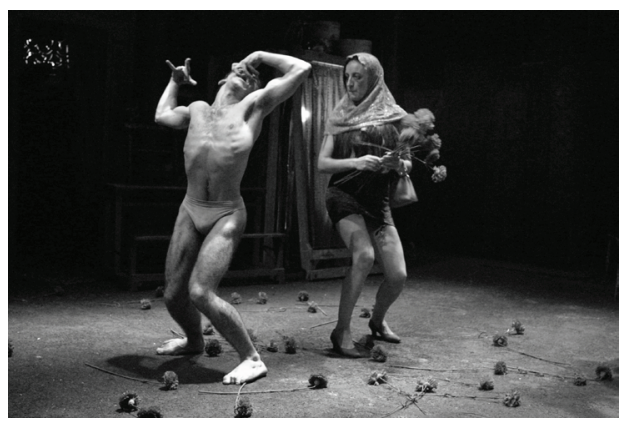

Cena de Mira’m. Foto de Manuel Fernández. Paródia de um motivo romântico da corte à mulher no sistema patriarcal.



Cena de Mira’m. Foto de Manuel Fernández. Pintura de rostos. Intervisualidade com retratos de Bacon.

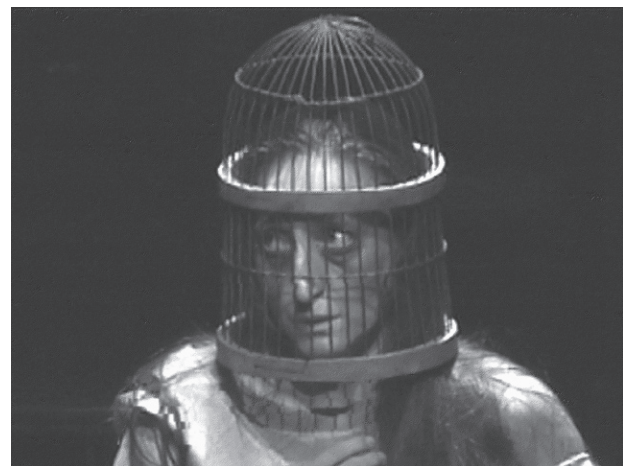

Cena de Mira’m. Paródia do discurso patriarcal. A ave cantora enjaulada. 


\section{Urdimento}

Este espetáculo está impregnado de intervisualidades com a história da pintura. ${ }^{21}$ Além do tenebrismo é evidente o expressionismo na pintura das faces e corpos que se podem relacionar com Francis Bacon.

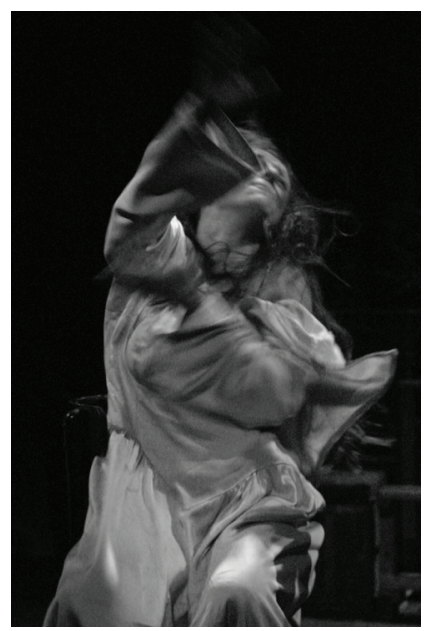

${ }^{21}$ Também se adverte neste espetáculo, por exemplo, elementos do expressionismo com sua tendência a representar seres humanos em posições e rostos desgarrados. Há quem há assinalado a intervisualidade com as pinturas de Francis Bacon. Alfonso de Toro destacou uns referentes de Bacon no teatro de Eduardo Pavlovsky.

Cena de Mira’m. Contorção dos corpos.
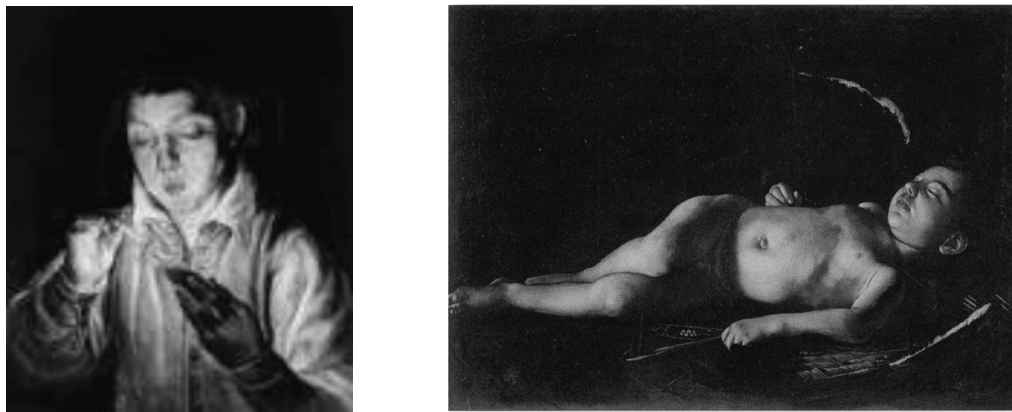

À esquerda, Greco. "El niño de la candela". À direita, Caravaggio. "Cupido dormido". Exemplo de tenebrismo.

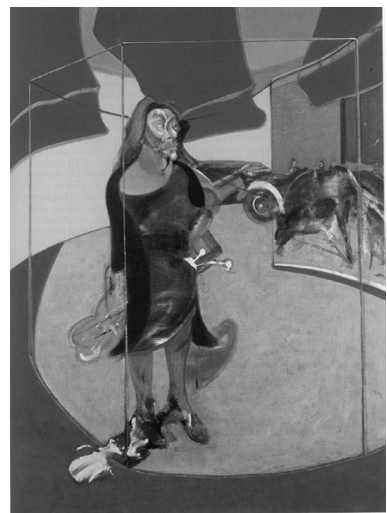

Bacon. "Retrato de Elisabeth Rawsthorne em uma esquina no Soho em 1967".

Da intervisualidade: pintura e teatro. Juan Villegas. 
Utilizam-se motivos tradicionais da pintura de Ocidente. Um caso é o da cena em que a personagem "feto", que ao se deslizar em um carrinho de mão, estira a mão com o dedo, querendo alcançar a mão do "homem” que aparece nas sombras, apenas com o braço iluminado. O motivo é o mesmo da cena da Capela Sistina, pintada por Michelangelo, naquele homem que trata de alcançar a mão estirada de Deus. Semelhante é a situação da cena do banquete de melancias no final do espetáculo, quando todas as personagens estão sentadas à mesa, com os rostos dirigidos ao público, que se associa com os quadros da Última Cena, motivo religioso tradicional da pintura do Ocidente, agora transportado ao carnavalesco e grotesco, tanto na figura das personagens como em seu comportamento. Ainda que não existam referências nas declarações de Marta Carrasco, creio que sua utilização do tenebrismo corresponde, além de suas preferências visuais pessoais, a uma tendência contemporânea, a que não se deve somente a fatores estéticos, mas também ideológicos. Em outros espetáculos, é possível pensá-lo como um signo da pós-modernidade e seu processo de cancelamento e paródia dos princípios da modernidade. Deste modo, a luz, como símbolo da razão e instrumento mais forte da Ilustração e o Progresso, deixa de sê-lo para ser um meio que evidencia as sombras, a escuridão criada pela razão. A luz é reveladora das sombras, dos males produzidos ou fundados nos princípios da Ilustração.



Cena de Mira'm. Fotos Manuel Fernández. Acima, Intervisualidade com Michelangelo. Abaixo, associável ao motivo de "A última ceia".

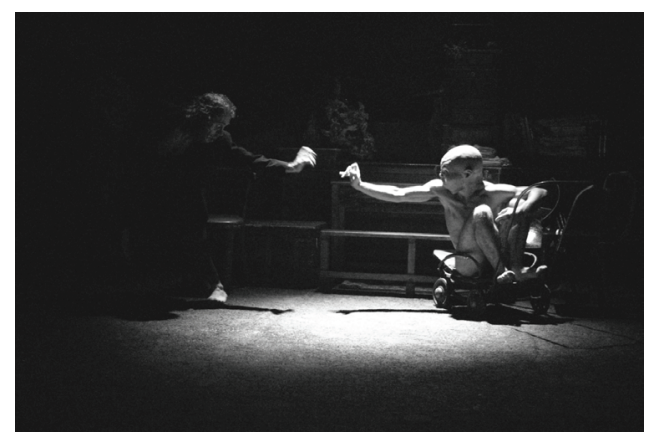




\section{Palavras finais}

A perspectiva proposta é que a análise do componente visual no teatro supõe a existência de um sistema de imagens visuais no sistema cultural no qual funciona a prática cênica. Em distintos momentos históricos existe a possibilidade de diferentes referentes de imagens visuais utilizadas no teatro, de acordo com os deslocamentos dos sistemas de imagens legitimadas no âmbito cultural, a comunidade produtora e receptora dos espetáculos teatrais.

A competência visual do espectador implica o conhecimento formal e social dos modos de representação das artes visuais legitimadas no seu tempo, por quanto as representações teatrais com frequência fundam suas imagens naquelas que, de alguma maneira, adquiriram legitimação na cultura respectiva. No caso do teatro, com frequência estas são as estabelecidas pelas formas artísticas, especialmente as consagradas pela cultura dominante. No entanto, cada prática artística tem sua própria tradição e sua própria legitimação estética.

A inter relação com outras artes visuais legitimadas tem que ser vista na perspectiva e inserção do momento histórico, incluindo, especialmente, considerações sobre o grupo social produtor. Tanto este como as artes visuais vinculáveis ao grupo são fenômenos determinados historicamente.

\section{Referências bibliográficas}

BALME, Christopher. Cultural Anthropology and Theatre Historiography: Notes on Methodological Rapprochement. In: Theatre Survey, 1994.

BENEYTO, Carmen Gracia. La iconografía del actor como documento. In: Del oficio al mito: el actor en sus documentos. Coord. Evangelina Rodríguez. Vol. II. Valencia: Acadèmia dos Nocturns Escenes, 1997.

BOURDIEU, Pierre. Homo Academicus. Paris: Minuit, 1984.

Distinction. A Social Critique of the Judgement of Taste. Cambridge, Massachusetts: Harvard UP, 1984.

. Photography. A Middles-brow Art. Cambridge, UK: Polity P, 1990. . Sociología y cultura. México: Grijalbo, 1990.

BOZAL, Valeriano. Historia del arte en España. Madrid: Ediciones ISTMO, 1972.

CARLSON, Marvin. Places of Performance. New York: Cornell UP, 1992.

CORNAGO, Óscar. La vanguardia teatral en España (1965-1975). Madrid: Visor Libros, 1999. 
DOMENECH, Fernando. Incidencia del desarrollo social en la puesta em escena. In: ADE TEATRO. n. 39-49 (Octubre, 1994)

ELAM, Keir. The Semiotics of Theatre and Drama. New York: Methuen, 1980. ELKINS, James. Visual Studies. A Skeptical Introduction. New York: Routledge, 2003.

ERENSTEIN, Robert L. Theatre Iconography: An Introduction. In: Theatre Research International 22, 3 (1997).

FINTER, Helga. La cámara-ojo del teatro postmoderno. In: Criterios n.31, p.25-48, 1994 .

FISCHER-LICHTER, Erika. Theatre Historiography and performance Analysis: Differente Fields-Common Approaches? In: Assaph, 10 (1994). . Thoughts on Interdisciplinary Nature of Theatre Studies.In: Assaph n.12, p. 11-24, 1997.

GASCOIGNE, Bamber. World Theatre, an Illustrated History. London, 1968.

GIRALT, David. Breve historia del arte. Madrid: Ediciones Globo, 1997.

GOFFMAN, Erving. The Presentation of Self in Everyday Life. Garden City, New York: Doubleday Anchor Books, 1959.

GÓMEZ, José Antonio. Historia visual del escenario. Madrid: La Avispa, 1997. GRAELLS, Antoni Ramon. Las nuevas arquitecturas y la puesta en escena. In: ADE TEATRO. n. 39-49 (Octubre 1994).

HARTNOLD, Phyllis. The Theatre. A Concise History. New York: Thames and Hudson, 1985.

HECK, T. F. (Ed) Picturing performance: The Iconography of the Performance Arts in Theory and Practice. Rochester: Rochester University Press, 1999.

HERAS, Guillermo. Investigación tecnológica y puesta en escena. In: ADE TEATRO n. 39-40, octubre, 1994.

HODGE, Polly. Photography and Contemporary Spanish Theater: Kaleidoscopic Modes of Dramatic Representation. Diss. University of California: Irvine, 1995.

KATRITZKY, M.A. Aby Warburgs. Costumi teatrali, (1895) and the Art Historical Foundations of Theatre Iconography. In: Theatre Research International 24.2 (1999). LOTMAN, Jurij M. y BORIS A. Uspenskij. Sobre el mecanismo semiótico de la cultura. In: Semiótica de la cultura. Madrid: Ediciones Cátedra, 1979.

MASSIP, Francesc. El análisis del teatro a través de la iconografía. Una metodología interdisciplinar (El espetáculo desde la edad media al barroco). In: GESTOS 44 (abril 2004).

PALLA, María José. Traje e pintura. Lisboa: Editorial Estampa, 1999. . A palavra e a imagem. Ensaios sobre Gil Vicente e a pintura quinhentista.

Lisboa: Editorial Estampa, 1996. 
PAVIS, Patrice. Diccionario del Teatro. Dramaturgia, estética, semiología. Barcelona: Paidós Ibérica, 1998.

El teatro y los medios de comunicación: especificidad e interferencia. In: GESTOS 1, 1986.

PILBROW, Richard. Stage Lighting: the art, the craft, the life. New York: Design Press, 1997.

PLAZA, Chillón, José Luis. Tendencias de la escenografía teatral en España de 1920 a 1936. Entre la tradición y la vanguardia: de Salvador Alarma a Maruja Mallo. In: Teatro, 13-14 (junio 1998-junio 2001).

Clasicismo y vanguardia en La Barraca de F. García Lorca: 1932-1937, de pintura y teatro. Granada: Editorial Comares, 2001.

QUEROZ, José Manuel. El problema del lenguaje plástico: notas sobre la doble articulación do signo pictórico. In: Signa Revista de la Asociación Española de Semiótica n. 3, 1994. Disponível em: <http://www.cervantesvirtual.com/hemeroteca/signa> ROMERA CASTILLO, José. Repertorios extraverbales en la comunicación literaria. In: Signa Revista de la Asociación Española de Semiótica n. 3, 1994. Disponível em: <http://www.cervantesvirtual.com/hemeroteca/signa>

y Francisco Gutiérrez Carbajo, eds. Teatro histórico (1975-1980). Textos y representaciones. Madrid: Visor Libros, 1999.

RUBINSTEIN, Ruth. P. Dress Codes. Meaning and Messages in American Culture. Boulder, Colorado: Westview Press, 1995.

RUSSELL, John. Francis Bacon .New York: Thames and Hudson, 1993.

RUSSEL BROWN, John. The Oxford Illustrated History of Theatre. Oxford: Oxford University Press, 2001.

VILCHES de Frutos y DOUGHERTY, Dru. Los estrenos teatrales de Federico García Lorca (1920-1945). Madrid: Taba Press, 1992.

VILLEGAS, Juan. El teatro histórico como discurso e instrumento de apropiación de la historia. El teatro histórico. 1975-1980. Romera y Carbajo, eds. Madrid: Visor, 1999.

El discurso teatral como construcción visual: la interrelación tecnología y culturas legitimizadas en la historia del teatro." Imagem de la cultura y el arte latinoamericano.(Universidad de Buenos Aires). v. 1, n. 1 (Noviembre 1999).

La interpretación del teatro como construcción visual. Irvine, Ca. Ediciones de GESTOS, 2000.

. On History of Theater and Theater as Visual Construction. Patrice Pavis,

Editor: La théatrologie: Questions de méthodes. Degrés 29, n. 107-108.

. Modos de referencialidad visual e historia del teatro. In: Escena y realidade.

PELLETTIERI, Osvaldo (editor). Buenos Aires: Galerna, 2003. 


\section{Urdimento}

Andrés Pérez: Poética teatral en tiempos de globalización y transnacionalización. In: Apuntes, 2000.

Pragmática de las culturas de América Latina. Madrid: Ocnos, 2003.

Del grotesco desgarrado en el teatro español contemporáneo: El caso de Mira'm se dicen tantas cosas de Marta Carrasco. In: El próximo acto: El teatro español en el siglo XXI. Ed. Sandra Harper and Polly Hodge. Doaware, Ohio: Estreno, 2006.

. Sistemas de referencia visual e historia del teatro: notas sobre pintura y teatro. In: Teatrae. 7, 2003.

Historia multicultural del teatro y las teatralidades en América Latina.

Galerna: Buenos Aires, 2005. 